\author{
IJ Malhotra \\ MBA graduate, ISMA University af Applied Sciences \\ 1 Lomonosova str., bld. 6, Riga, LV 1019, Latvia \\ E-mail: ifsha.malhotra@gmail.com \\ ORCID: 0000-0001-8129-6963 \\ J Dehtjare \\ ISMA University af Applied Sciences \\ 1 Lomonosova str., bld. 6, Riga, LV 1019, Latvia \\ E-mail: jevgenija.dehtjare@isma.lv \\ ORCID: 0000-0002-6859-2327
}

\title{
The online marketing complex in tourism
}

\begin{abstract}
The article discusses the online marketing complex of tourism and socioeconomics of the online-tourist industry. The analytical data will enable to understand the current business trends in the competitive market today. The key objective of this research is to examine the eTourism developments around the world and in Greece as a country that is gradually embracing eCommerce. The prospect of the online-tourism is presented on the example of Greece tourism website InThessaloniki.com. The research reveals the features of tourism business and discusses important milestones in its development. Although it is rapidly becoming a growing topic of research, the information on the websites seems to be the only rescue for the researchers. At the same time, it forewarns and forearms the marketers of tomorrow about its importance as future mode of acquiring information and purchase of tourism products and services. The analyse of the socioeconomics of the online-tourist industry will enable to understand the current business trends that are more competitive in the market than the exists today. It will provide an opportunity to attract new business customers and receive additional profit. The author assumes that the analyses of the online- tourism market technologies have been instrumental in increasing the domain of awareness and accessibility while reducing the uncertainty with respect to communication gaps. With future high projections in all the spheres of tourism, it's not gainsaying that technology can help us manage tourism operations better through ensuring high efficiency in working with clients, increase their loyalty and the sales rates of the company. The author analyse the socioeconomics, entrepreneurial activity, internal and external environment of the tourist industry.
\end{abstract}

\section{Keywords}

E-tourism, onlinetourism market, modern tourism, socioeconomic factors

JEL: M31, L83

\section{Introduction}

The advancement in Information Technology particularly the arrival of the Internet - has further expanded the scope of tourism to global markets. Online tourism, as its natural corollary has emerged to occupy a central place in tourism marketing. Due to its sheer potential, online tourism has become a buzzword uttering out from almost every tongue that speaks of tourism. The online travel market of $\$ 756$ billion during 2019 is anticipated to grow by $8 \%$. Overall the online travel booking market share makes up $63 \%$ of the $\$ 1.2$ trillion the travel industry generates every year. [1] The increasing competitiveness in the global tourism market encourages tourism operators to investment more in promotion, resources, knowledge and quality in order to achieve satisfactory growth. Therefore, it is extremely important to be in touch with the latest technological trends and have the knowledge required to effectively respond to the challenges of global competition. Internet technology provides high-quality and efficient operations in all economic sectors, including the tourism industry. In this paper, the market complex of the tourism industry caused by the introduction of Internet technology and the part it plays on the onlinetravel agency were analysed. 
Object of the research: Entrepreneurial activities of an online travel agency InThessaloniki.com.

Subject of the research: A process of an online platform impact and its promotion to the entrepreneurial activity of InThessaloniki.com.

Aim of the research: To analyse the impact of socioeconomic factors of an online activities in tourism industry and to study marketing complex on example of InThessaloniki.com.

\subsection{OBJECTIVES OF THE RESEARCH:}

1) To analyse trends of modern tourism market development

1) To analyse current perspectives of an online marketing strategies in tourism

1) To develop an analysis on the tourism company's impact on the country's economy

1) To understand the marketing complex of InThessaloniki.com

1) To estimate the competitive nature of an online travel business nowadays

1) To propose a set of measures to improve online marketing complex in tourism on example of InThessaloniki.com.

The research will mainly constitute theoretical, practical and graphical analysis of the companies undertakings and strategies, through statistical analyses of both primary and secondary data.

\section{Theoretical background}

This chapter covers the theoretical part of the research. It explores the growth of online tourism and its impact on the economy.

\subsection{EMERGENCE OF ONLINE- TOURISM MARKET}

Online Tourism has been defined as a new form of travel product distribution where a supplier/ service provider offers products/services mainly through the medium of Internet to a group of customers, irrespective of their physical location (Singh 2003). [2] 2.1] Online tourism equips a tourist, tour operator or travel agent for convenient exchanges using electronic medium. Unarguably, online tourism has successfully emerged as a platform that enables direct bookings, electronic payments, Business to Business (B2B) and Business to Consumer (B2C) trading among product marketers, travel agents, resellers and customers. A comparison of tourism statistics reveals that there has been an extraordinary increase in the number of tourists in the last 50 years. The number of international tourist arrivals has evolved from a mere 25 million in 1950 to 1.4 billion in 2019 , compounding to an average annual growth rate of around 1.7 trillion(\$) since the emergence of online-tourism services [2].

\subsection{DEVELOPMENT OF INTERNET IN TOURISM-MARKET}

The appearance of the Internet and the incredibly rapid development of highly sophisticated computer and telecommunication technology has made the world a global village in a real sense. The Internet has become a support to more complex and critical functions in tourism and hospitality industry and it contributes to its significant innovation. Due to the appearance of the Internet, there have been some changes in the tourism subjects business and those are the following:

1) Each serious subject in the tourism and hospitality industry has a website that can be classified into four broad groups: 'holding corporation identity websites, chains, concession and membership websites, websites of individual sites and facilities, and portals and vortals.'(Koelzer, W., Cox, B., 2005).[2] 2.2] 'Portal can be defined as a vehicle that offers a rounded set of services for specific well-defined group of users.'(Kalakota, R., 2002).[2] 2.3] 'Vortal is a website that provides information and resources about a particular and specific industry.' (Webopedia - On line Computer Dictionary for Computer and Internet Terms and Definitions).

2) 'The Internet offers the possibility of expansion, rapid data transfer and flexibility (websites can always change, the changes are immediately visible and are not limited to space and time).'(Raza, I., 2006). [2] 2.4]

3) 'Contemporary business in tourism market is characterised by the implementation of various booking systems into business systems of travel agencies, hotel chains, airlines, car rental companies and other participants in tourism product formation.'(Dobre, R., 2005).[2] 2.5]

4) Organisation and distribution costs are decreased in various tourist subjects business conducting (travel agencies, hotel chains, independent hotels...).

5) New intermediaries on the Internet are created and traditional ones must change their role.

6) The Internet allows high-quality and effective market research and 'industrial espionage'.

Gone are the days where travel booking and reservations were only possible by visiting travel agencies or ordering by phone - travel websites and mobile apps have been making digital travel arrangements increasingly easy.The on-line tourism is flourishing in the world rapidly. Many International companies have emerged on the face 
of the globe, which are engaged in on-line tourism.

This timeline shows the online travel sales worldwide from 2014 to 2020. In 2016, global online travel sales totalled 564.87 billion U.S. dollars. This figure grew to 755.94 billion U.S. dollars in 2019 and is projected to grow upto

\section{Digital travel sales worldwide from 2014 to 2020}

\section{(in billion U.S. dolliars)}

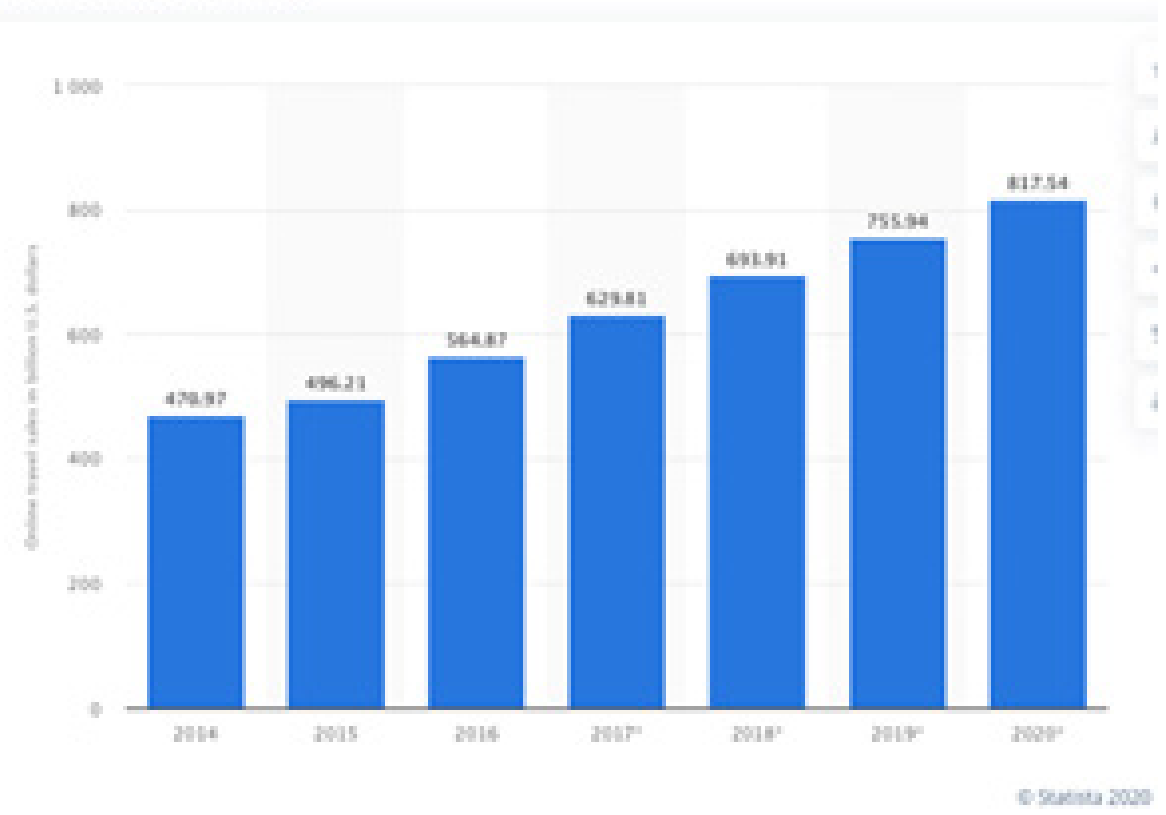

Figure 1 Digital travel sales worldwide. Source: statista.com

817.54 billion U.S. dollars in 2020 [3].

\subsection{ANALYSIS ON ONLINE-TOURISM AGENCY}

1) For the travel agencies and tour operators business, the Internet has shown to be a profitable medium of tourism promotion and sales.

2) "The Internet represents an interesting and useful distribution channel for collecting clients and it provides the ability to identify their desires.' (Čavlek, N, 2000) [2] 2.6].

3) Promotional visualisation of tourism services and products through multimedia technology leaves greater impression on potential customer than standard brochures, catalogues and leaflets.

4) Overbooking has become almost impossible because all communication problems that may cause it are removed.

5) The Internet allows the improvement of travel agencies and tour operators by speeding up communication and providing all the necessary information.

6) Product distribution and services of agencies do not depend on the quantity of printed catalogues anymore and information about them can reach millions of the Internet users.

7) The Internet provides selling services of travel agencies on demand.

8) CRS/GDS systems allow better and more efficient business with clients to contemporary travel agencies.

9) Greater added values which agencies, by using the Internet, can provide to clients are high-quality information, quick offer of services related to travel.

Use of the Internet in contemporary travel agencies business has certain drawbacks such as: web information is not always complete and reliable, payment security is still not on the satisfactory level, and the sale of certain products and services demands direct communication with the travel agent.

\subsection{ONLINE-TOURISM AGENCY MARKETING ACTIVITIES}

Marketing is an integral part of conducting business in tourism, with the Internet becoming an essential part of media planning. The Internet provides readily available information to potential customers from around the world and it represents an important 'marketing and communication channel' that can effectively connect the subjects of offer and demand in contemporary tourism. The increasing competitiveness in the global tourism market demands of the tourist agency exceptional efforts and investments in promotion, resources, 
knowledge and quality in order to achieve satisfactory growth. Therefore, it is extremely important for each travel agency to follow new technological trends and to have the knowledge required to effectively respond to challenges of global competition. In or- der to implement the marketing concept in business of travel agencies, it is necessary to meet certain requirements.

Firstly, it is necessary for market- ing to be understood and accepted first by governing bodies of the agency, its individual organisational units and then all employees of the agency.

Secondly, marketing applied as a business concept operates through its functions. The content of these functions in the agency should be precisely defined before implementing marketing organisations and setting up marketing services. Marketing activities of contemporary travel agencies, which greatly enhance business through the Internet, can be highlighted in the following areas: (Dulčić, A., 2005) [2] 2.7].

1) Promotion of tourism services - current assets: TV, radio, newspapers, catalogues, pamphlets, posters, the screen technique; it is improved with promotional text, drawings, photographs and sound, 3D space, 3D photographs, media interaction.

2) Tourism services sales - unlimited database and unlimited capacity of digital media allows instant access to the tourist market free products to every potential tourist.

3) Tourist services booking - instantaneous communication between all participants of the sales process; it allows 'booking on demand', i.e. avoids excessive sales (overbooking).

In order to perform these marketing activities, particularly in selling travel packages, use of the following technologies stands out:

1) World Wide Web (the system of linked pages) use

2) Mail connection (for sending and receiving e-mail)

3) Multimedia - 'a combination of different media: text, sound and images, all computercontrolled.'(Colin, S., 1993) [2] 2.8].

4) Databases: by using the Internet, multimedia and databases it can be achieved the following: a rational and fast online communication, direct contact with the market and its business partners, integration and automation of business process, delivery and access of information. Kent, P. (1994)[2] 2.9].

\section{Review of Online-tourism in Greece}

Greece is one of the most popular tourist destinations worldwide in terms of arrivals and it is currently ranked as the 15th most visited country by the World Tourism Organisation (WTO). In 2018, the Greek Travel \& Tourism sector grew at a rate of $6.9 \%$ - over three and a half times the pace of its wider national economy, which grew by $2.0 \%$. The sector represents $20.6 \%$ of Greek GDP compared to the global average of $10.4 \%$. This means that one in every five Euros spent in Greece last year came from the Travel \& Tourism sector, worth $€ 37.5$ bn (USD \$44.6 bn) [4].

However, The share of travel organised online in Greece has increased to an estimated $17 \%$ from just $7 \%$ in 2012 which is fairly low as compared to other countries [5]. The low level of the online organised travels is mainly because of the limited available online content compared to the rest of the, competitive, countries. To this the author draws great attention to the tourism popularity in Greece yet lack to effective online-marketing which need to be fulfilled in the current competitive times. A real increase in competitiveness, tourism demand and employment is driven by the increase in online content. A clear return in terms of additional job creation has been calculated for the Southern European countries including Greece. Over the past four years, Greek tourism arrivals rose $50 \%$ : well ahead of average demand growth of $14 \%$ from major source markets. Online searches for Greek tourism rose $46 \%$ over the same period [6].

The author suggests, to fully achieve these opportunities, the tourism industry must:

- Be aware of the demand for online information in source markets;

- Expand the number of businesses selling online;

- Ensure the most popular sales platforms are being used for source markets;

- Provide opportunities for smaller business to reach a wide audience;

- Provide relevant information online, including translation into key languages;

- Ensure clear information relating to cultural attractions is available;

- Make use of the most popular platforms being used for research;

- Engage with potential tourists using social media to encourage information sharing;

- Encourage feedback through reviews and social media.

\subsection{TOURISM IN GREECE CITY OF THESSALONIKI}

Thessaloniki is a city that in theory can perfectly fit in the city break destination tourism development format. Being the second in terms of population city in Greece, Thessaloniki has a lot of characteristics for a tourism development success story.

In 2009 Lonely Planet ranked Thessaloniki, the 


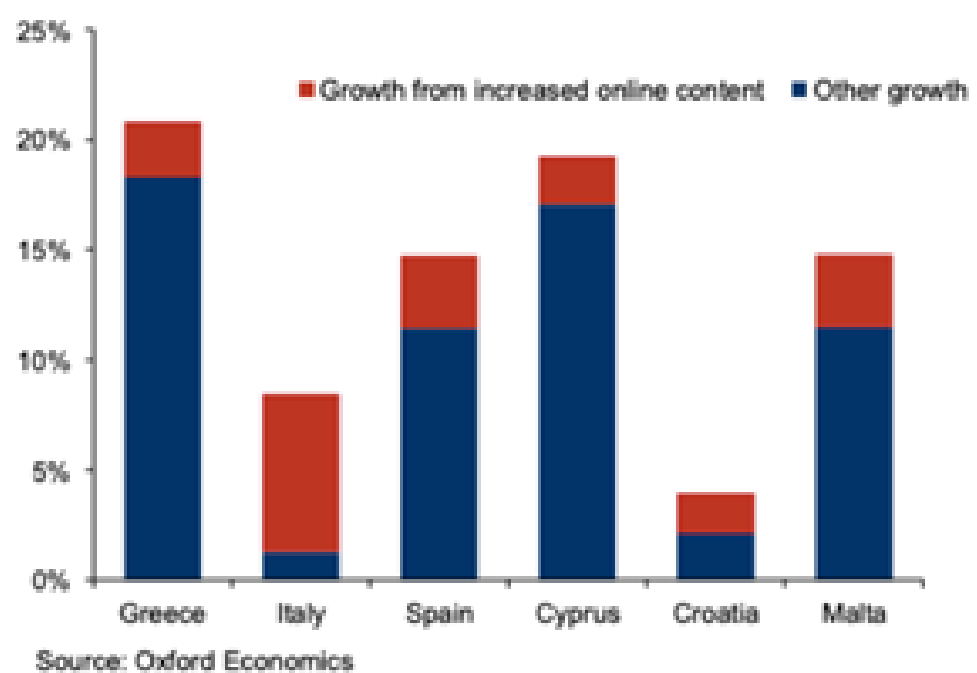

Figure 2 Market gains from increased online content 2019 in Europe (in\%) Source: Oxford Economics

country's second-largest city, the world's fifth best "Ultimate Party Town", alongside cities such as Montreal and Dubai [7]. Apart from that, Thessaloniki was the European Youth Capital in 2014 [8]. The Association of British Travel Agents, meanwhile, ranked the city among the 12 destinations "to watch for" in 2019, thanks to its new flight connections, its big public events and its value-formoney rating [9].

In conclusion, there are many opportunities for the city to explore in order to enhance its tourism performance.The development of specialised onlineproducts for targeted market would probably attract higher market share. Building a strong brand and a competitive product proposition can be the next step as considering the example for the city tourism portal - InThessaloniki.com.

\subsection{REVIEW OF THE ONLINE- TOURISM AGENCY OF GREECE - INTHESSALONIKI.COM}

The enterprise that is considered in this work and based on the activity that will be further analysed is the onlinetravel company "InThessaloniki. com". The website is an online travel guide and service provider. The so-called website named inthessaloniki.com came in from 2014 winning the search engine "competition" being for many keywords on the first places of google results over taking all the other. The company has two ownersfounders (Patsogiannis Konstantinos \& George Chatzifotis).

Initially, the company specialised as an onlineservice provider for tourists. The target customers are mainly foreign travellers intending on sightseeing tours and accommodations around Thessaloniki, Greece. Therefore, the website put all its efforts to install awareness and confidence in its services, including update with coming events, festivals and city's major attractions. The website also displays several article and information relevant to the city and its customers interests. Each year the client base has expanded, it because necessary to launch new markets and differentiate the service from its competitors, particularly through updated service and accessibility.

One of the key factors in achieving and maintaining the competitive advantage of travel website in the market is the high quality of services provided and customer satisfaction. In this research the author aimed to assess and to distinguish the factors that play a great role during the assessment of the quality of services the travel agencies offer such as:

1) The image of a travel website;

2) Web-pages;

3) Recommendations and reviews from the tourists and users;

4) Featured services and updated information;

5) Casting clear images;

6) Clear pricing;

7) Map integration;

8) Search filters;

9) Augmented search;

10) Predictive search;

11) Easy booking system;

12) Interesting facts or articles.

\section{The analysis of structural problems and} challenges of an the online-tourism agency

Despite its popularity and growth over the years, the online-tourism industry has reached a stage where both its potential and competitiveness have become questionable. The author consider structural problems and challenges in this context:

1) Gradual deterioration of tourism product 
and lack of reinvestment in improvements;

2) Increase of tourism arrivals but decrease of tourism expenditure per capital;

3) Inadequacy of the tourism planning process;

4) Dependence upon major tour operators for promotion and distribution;

5) Inappropriate and ill-timed marketing campaign which has little effectiveness;

6) Inadequacy of information to serve the everexpanding demand;

7) Lack of coordination at the destination and disrespect for tourists' needs;

8) Lack of professionalism and training in both state and private tourism establishments;

9) Unsuccessful and inconsistent programmes of government intervention;

10) Development of tourism as a single regional development option;

11) Oversupply of tourism amenities and fierce price competition;

12) Failure of the private sector to invest in long-term projects;

13) Inadequate distribution mechanisms which generateover dependence on intermediaries;

14) Failure of both the private and public sectors to learn from internationally gained experience in tourism development and marketing;

15) Lack of tourism research to identify the impacts of tourism;

16) Negligence with regard to new tourism demand challenges;

17) Preference of variant on-line or face-to-face transaction.

To conclude the online-tourism industry has seen increase in sales and its profits but yet there are variant problems and challenges which are yet to be considered but mostly ignored by onlinetravel agencies, as also in this case of the research on the example of InThessaloniki.com.

\section{The need to improve tourism marketing website}

In this regard, it is appropriate to offer some recommendations for its improvement, concluding to this the author underlines several innovative and observation as:

1) The electronic site has to provide comprehensive and reliable information corresponding to the demand, which implies adequate response to tourism enterprises on updating existing content.

2) The price outlines limits to the potential client and sometimes stands out as a factor with a dominant role in the final purchase decision. Its lack can arise suspicion and doubt. From a marketing standpoint, the price may serve as a mechanism for short- term market impacts, and in particular, to change demand for particular travel products for a certain period, resulting in sales increase.

3) The electronic tourism site has to offer quality content in handy format for the client with professional photos, attractive video for the destination and the tourist object, its products as well as and user content / ratings and review.

4) The client is interested in how to get to the hotel or restaurant, or if there is a car park nearby, so the availability of such information in the site is essential and useful for the client hence creating high interest in the website.

5) The electronic site has to perform fast page loading and the tourist enterprise to invest in responsive web design.

6) The structure of the site and reservation form has to be simplified and web addresses to be brief.

7) The site is recommended to be translated into a minimum of four languages in order to attract foreign customers.

8) In order to increase the number of reservations the tourist object may consider diverse methods of guaranteeing the reservation, as well as for the payments: bank credit, debit card, electronic payment systems, and during off-season periods reservation guarantee should not be required.

9) Feedback from consumers is mandatory.

10) Another important goal should be to maximise the potential of the electronic site for the sale of tourist packages. The packages allow adding value to the accommodation service by discreet pricing.

11) The service packages can be offered at promotional prices in order to stimulate demand.

12) It is appropriate to maximise the ability of the tourism website to announce the promotions.

13) Planning promotions in periods of low demand or on specific occasions, must be announced online in order to consolidate the image of the website as the most current and accurate source of information about the product offered in order to motivate the use of inputs for corporate clients on the website of the tourist business.

14) The process requires continuous initial training on the preparation of various tariff plans and passwords for access to customers

15) Constantly revise the presence of the tourist sites on the Internet and to take appropriate action in the event of incorrect information 
published on partners' websites.

\section{Conclusion}

Development of electronic and information technologies enables tourism businesses to react adequately on individualised tourism demand. The innovative marketing tools, which are based on web technology expands the trajectory in the dimensions of marketing. It includes new marketing tools that help improve the marketing activities in tourism. It was revealed that online-tourism is less dependent on only tourists but more resistant to local aspects and other manifestations of economic instability in the country. Analysing the research elements, considering the trends and prospectives studying marketing strategies in tourism industry and the influence of E-tourism in order to further propose suggestions to improve entrepreneurial activities of an online-tourism agency.

\section{References}

[1] Singh, Simarprit 2003 www.compareinfobase.com, paper presented in Seminar on Role of IT in Tourism Promotion, Lucknow

[2] Koelzer W, Cox B 2005 Internet marketing -hotels, restaurants and tourism, Zagreb, M plus

[3] Kalakota R 2002 E-business 2.0. Zagreb, Mate Webopedia- On line Computer Dictionary forComputer and Internet Terms and Definitions E-source: www.webopedia.com

[4] Raza I 2006 Full Beds-Marketing in tourism, hotel management and catering Zagreb, M plus.

[5] Čavlek N 2000 Fever gripped tour operator UT, 4/2000

[6] Dulčić A 2005 Travel agencies: business and management Split, Ekokon

[7] Colin S 1993 How multimedia works

[8] Kent P 1994 Internet guide

[9] Online travel booking statistics E-source: https://www.condorferries.co.uk/online-travel-bookingstatistics

[10] Data E-source: https://ourworldindata.org/tourism

[11] Source E-source: https://www.statista.com/statistics/499694/forecast-of-online-travel-salesworldwide/

[12] GTP report E-source: https://news.gtp.gr/2019/01/31/greece-breaks-all-tourism-recordswelcomes-33-milliontravelers-2018/

[13] Greece profile-European Union E-source: https://ec.europa.eu/health/sites/health/files/state/ docs/2019_chp_gr_english.pdf

[14] Tourism economy-Impact of online content-Greece E-source: https://d1iydh3qrygeij.cloudfront.net/ Media/Default/landing-pages/recent-releases/2017/TE_Google\%20Greece\%20ES\%20report\%20 2017.pdf

[15] Palm beach E-source: https://www.palmbeachlwp.com/archive/greeks-try-to-find-way-toithaca/

[16] European youth forum 2014 E-source: https://www.youthforum.org/european-youth-capitalwinnerthessaloniki-2014

[17] Greece-is.com E-source: https://www.greece-is.com/northern-light-thessalonikis-futurebrighter-ever/6 